\title{
Microstructural Characterization and Mechanical Properties of New Grade Al-Li Alloy
}

\author{
Aezeden Mohamed \\ Faculty of Engineering and Applied Science, Memorial University, St. John's, NL, A1B $3 X 5$
}

\begin{abstract}
A new grade of Al-Li alloy, C460, was solution treated at $550^{\circ} \mathrm{C}$ for 3 hours, cold water quenched, and then aged at $200^{\circ} \mathrm{C}$ for 24 hours. Heat treatment produced a $\delta^{\prime}$ precipitate. In tensile and fatigue tests the precipitate was sheared by moving planar dislocation bands in response to cyclic stress strain. Results show that the $\delta^{\prime}$ precipitate has a significant effect on the tensile and the low-cycle fatigue behavior and on the microstructural characterization. Also, the alloy appears to undergo cyclic hardening, saturation, and softening, especially at lower plastic strain amplitudes. Scanning and transmission electron microscopy revealed $\delta^{\prime}$ precipitates and planar dislocation bands forming during plastic deformation.
\end{abstract}

Keywords: - C460, dislocation, fatigue, precipitate, tensile.

\section{INTRODUCTION}

Studies of aluminum-lithium alloys are important especially for applications where weight and strength are critical properties such as in the aerospace industry. Studies have primarily focused on strain localization obtained from S-N and cyclic stress strain curves with other recent investigations looking at tensile deformation behavior [1-3]. The shear deformation that formed during tensile and cyclic stress strain testing has received careful investigation by material science researchers during the last two decades. These studies concentrated on mechanical properties and their analysis [4-6]. One of these recent studies was an analysis of the microstructures that formed during tensile and low cycle fatigue testing with particular emphasis on the complex relationship between precipitates, the type of dislocation that occurred during plastic deformation, and dislocation morphology $[7,8]$.

The goal of these basic studies was to improve the mechanical properties of these alloys, especially the fracture toughness which is a limitation of Al-Li alloys. For this reason, these alloys have not been used much in the aerospace industry compared to, for example, the more conventional aluminum alloys such as $\mathrm{Al}-\mathrm{Cu}$ and $\mathrm{Al}-\mathrm{Zn}$. Although the fracture toughness behavior of $\mathrm{Al}-\mathrm{Li}$ alloys had been widely studied, it remains an interesting, important and challenging research subject $[9,10]$. Recently, materials scientists developed a new Al-Li alloy grade called C460 with improved ductility and fracture toughness, while maintaining high strength. This new product is a result of improved technologies for refinement of processes for controlling microstructural features (grains, secondary features) and dispersion hardening. Thus, more study is needed on Al-Li alloys, especially the new grade alloy C460, of their mechanical properties through testing for stressstrain and cyclic stress-strain curves, on the correlation of the alloy's microstructural characteristic, and on the interaction between dislocations and precipitate morphologies.

The objective of the research described in this paper was to study the mechanical strength and fatigue resistance under tensile and cyclic stress strain testing and to correlate the experimental data with microstructural morphologies developed during testing, including the interaction of precipitates and development of dislocations.

\section{MATERIAL AND METHODS}

C460 was supplied by Alcoa Aerospace with a chemical composition (wt. \%) of $3.0 \mathrm{Cu}, 2.0 \mathrm{Li}, 0.8 \mathrm{Zn}$, $0.3 \mathrm{Mg}, 0.3 \mathrm{Mn}, 0.1 \mathrm{Zr}, 0.02 \mathrm{Fe}, 0.02 \mathrm{Si}$, and $\mathrm{Al}$ (balance).

The as received alloy was solution treated at $550^{\circ} \mathrm{C}$ for 3 hours, cold water quenched, then aged at $200 \mathrm{oC}$ for 24 hours. The heat treatment was performed in a protective argon atmosphere to avoid oxidation.

Test specimens were produced with a gauge length of $20 \mathrm{~mm}$. One batch was machined parallel (L, for longitudinal) to the rolling direction of the alloy and another batch perpendicular to the rolling direction ( $\mathrm{T}$, for transverse). Tensile and fatigue tests were carried out on an Instron Universal Testing machine at room temperature.

Microstructural observations were made in a scanning electron microscope (SEM) and a transmission electron microscope (TEM). Samples for the microscopes were sectioned and prepared by standard procedures. The operating voltage for the SEM was $20 \mathrm{kV}$ and $180 \mathrm{kV}$ for the TEM. The etching solution for the SEM 
samples was sodium hydroxide $(\mathrm{NaOH})$, whereas jet polishing with an electrolyte of $30 \% \mathrm{HNO}_{3}$ and $70 \%$ methanol was used for the TEM samples.

\subsection{Tensile and Cyclic Stress Strain Response}

\section{RESULTS AND DISCUSSIONS}

Figure 1 shows changes in the yield strength, ultimate tensile strength, fracture strength and \%elongation for the test specimens machined in two different orientations, viz. transverse and longitudinal orientations (T-1, T-4) and (L-2, L-3), respectively. From Figure 1, the ultimate tensile strength and fracture strength of both types of test specimen exhibited increases to maximum values. Ductility reached similar lowest values, i.e. $\mathrm{L}$ and $\mathrm{T}$ samples. Thus, the ultimate tensile strength, fracture strength, and ductility are independent of test specimen orientations (transverse or longitudinal). However, in the case of the yield strength there is a contrasting behaviour, with higher yield strengths for the longitudinal test specimens than for the transverse test specimens.

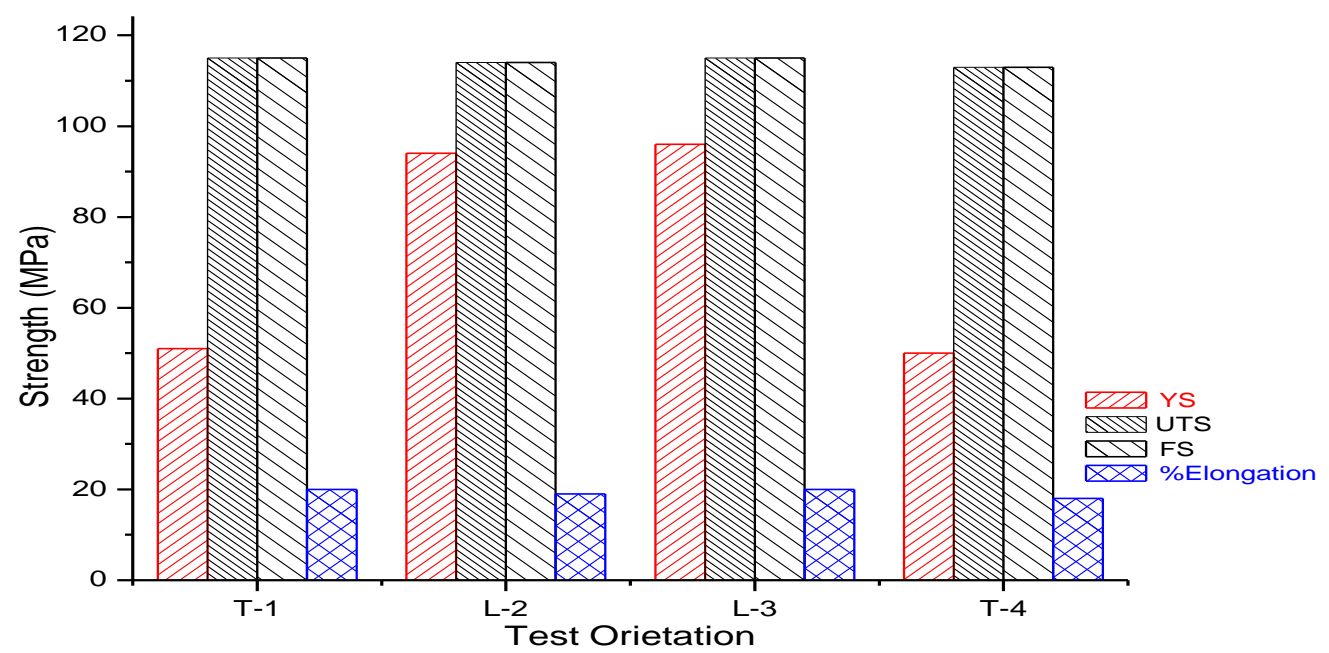

Figure 1 Show (YS) yield strength, (UTS) ultimate tensile strength and \% elongation properties of tensile test specimens in two orientations, $(L)$ longitudinal and $(T)$ transverse.

Figure 2 shows hardness data obtained in three different orientations - longitudinal $(\mathrm{L})$, transverse $(\mathrm{T})$, and short transverse, i.e. in the orientation of the thickness of the plate (ST). For these three orientations small differences in hardness values can be clearly seen, especially as between transverse (T) and short transverse (ST) orientations. The longitudinal orientation had higher hardness values than the transverse (T) and short transverse (ST) orientations.

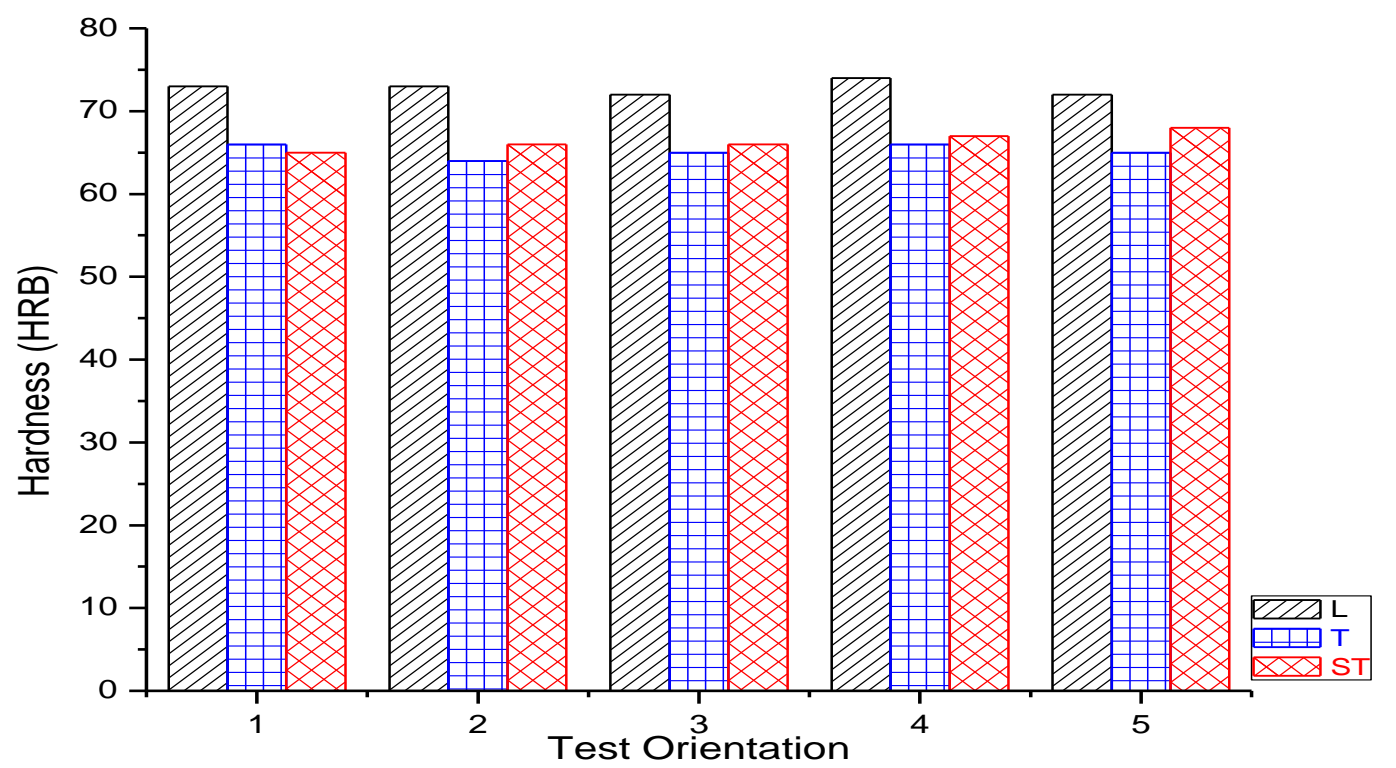

Figure 2 Hardness values in three orientations $(L)$ longitudinal, (T) transverse and (ST) short transverse. 
It should be noted that all tensile and low cycle fatigue tests specimens were aged at $200^{\circ} \mathrm{C}$ for 24 hours and were all longitudinal specimens, i.e. machined parallel to the rolling direction. It should be also noted that all low cycle fatigue test specimens were longitudinal (Figure 3 and Figure 4).

Typical hysteresis loops are shown in Figure 3. The first 50 hysteresis loops, which show initial cyclic hardening and a stable hysteresis loops at about 100 cycles, are shown in Figure 3 (a). Further saturation from approximately 500 to 1500 hysteresis loops is followed by cyclic softening as show in Figure 3 (b).

After cyclic softening, the specimen weakens and the final fracture stage is shown in Figure 3 (c). Beside the initial cyclic softening or hardening, the behavior in Figure 3 was typical of all tests.

Approximate half-life stable hysteresis loops can be used to obtain more information such as elastic and plastic strains and stress amplitudes.

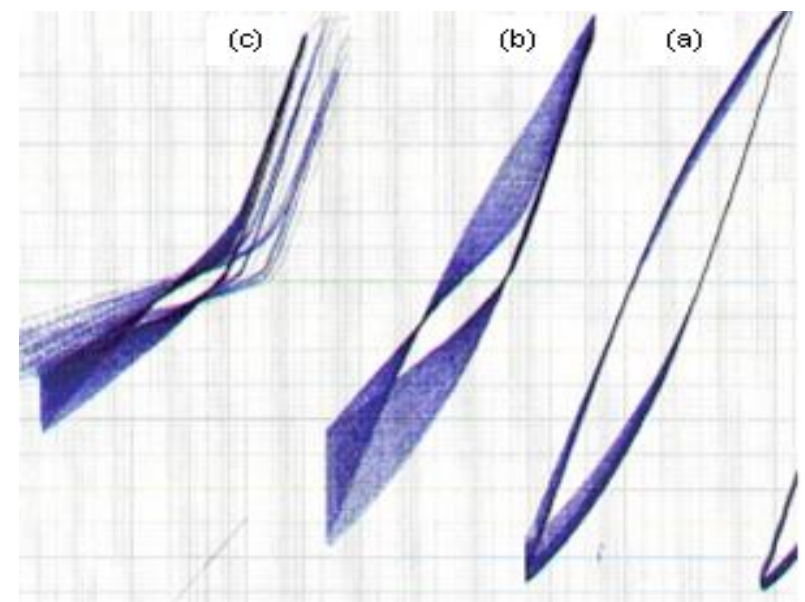

Figure 3 Example of low cycle fatigue hysteresis loops obtained from each test specimen of C460.

Figure 4 shows cyclic hardening at constant plastic strain amplitude in which the stress amplitude response varies with the plastic strain amplitude. Plastic strain amplitude decreases with stress amplitude, with the specimen exhibiting cyclic hardening, starting at the beginning of the early cycles. After approximately 100 cycles, specimens began to experience saturation for several hundred cycles, which was followed by cyclic softening till fracture. Such data on low cycle fatigue can provide important information on the mechanical stability of C460 alloy and for mechanical design, including estimating at what that time the material will either experience cyclic hardening or cyclic softening or both during cyclic stress strain testing. Furthermore, such tests can provide information at the micro-and-nano scale level for characterizing planar dislocations.

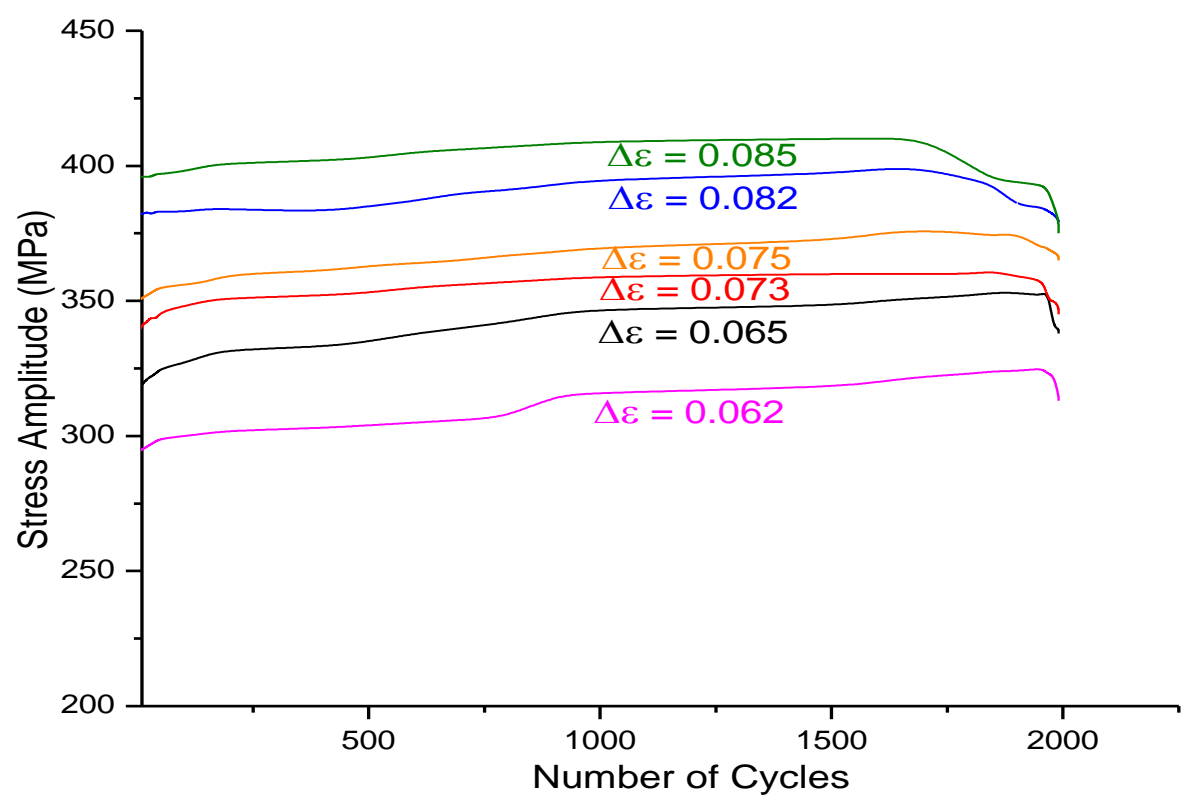

Figure 4 Stress amplitude versus number of cycles at different constant strain amplitudes $(\Delta \varepsilon)$. 


\subsection{Microstructural Characterizations}

In order to better understand the mechanical properties such as strength, fatigue resistance of the C460 alloy obtained from tensile and cyclic stress strain tests (Figure 1 and Figure 4), the samples were examined to determine whether precipitates were sheared or non-sheared and the morphologies of planar dislocation bands.

The interaction between dislocations and precipitates during plastic straining can significantly affect the strength, ductility and fatigue behavior of the alloy during low-cycle fatigue. Observations indicated an increased planar dislocation density as shown in Figure 5. Dislocations in the form of large planar slips were obvious and were responsible for shearing the $\delta^{\prime}$ precipitates (Figure 5 (a) and (b)).
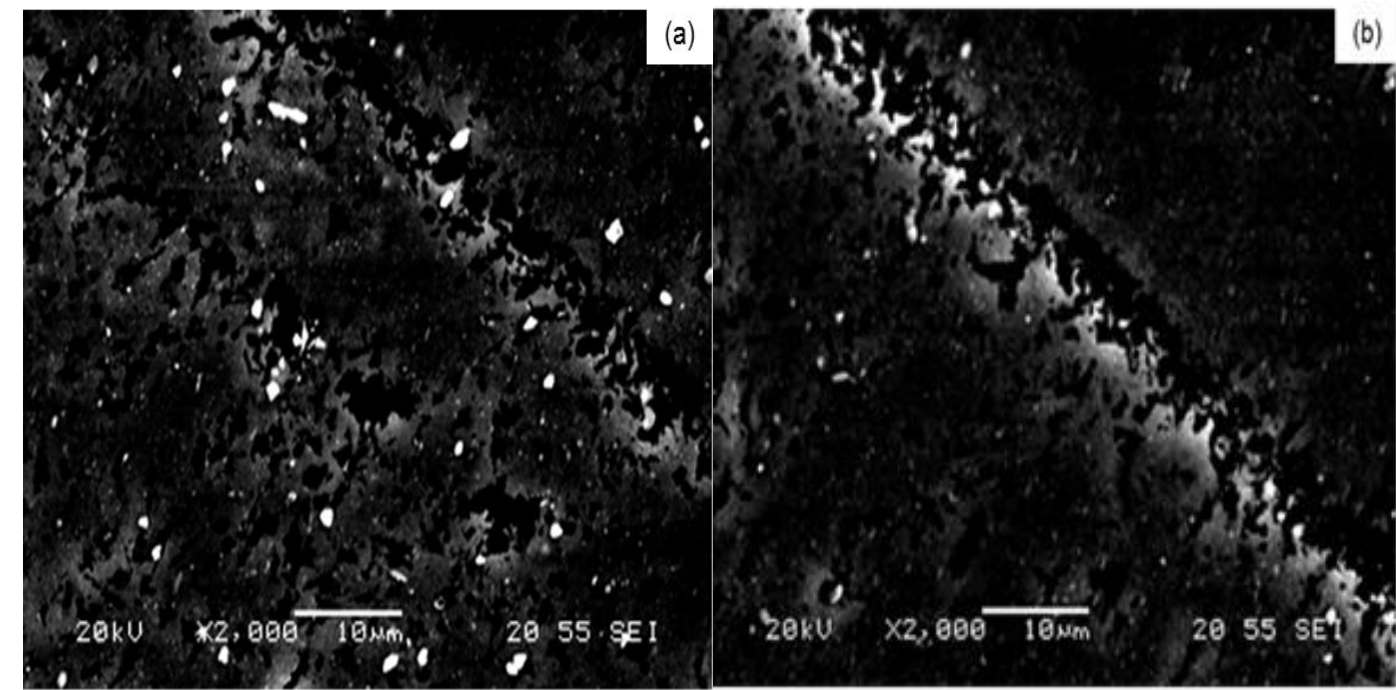

Figure 5 (a) and (b) SEM micrograph showing dislocation bands developed during fatigue testing and precipitates.

It can be seen that $\delta^{\prime}$ precipitates were largely produced during the application of heat treatment of the alloy (Figure 6).

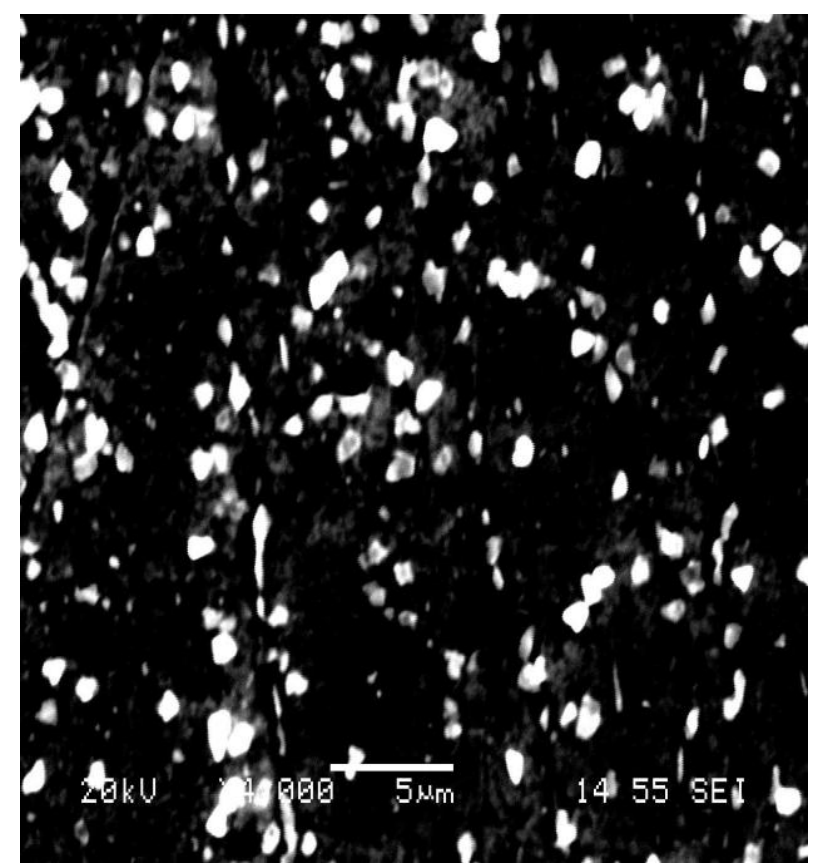

Figure 6 Large $\delta^{\prime}$ precipitates formed at $200^{\circ} \mathrm{C}$ in alloy aged for 24 hours.

Interactions between dislocation bands and $\delta^{\prime}$ precipitates exhibit intensive shearing. SEM observations gave clear details of the morphology of the $\delta^{\prime}$ precipitates before and after shearing as shown in Figure 6 and Figure 7 respectively. 


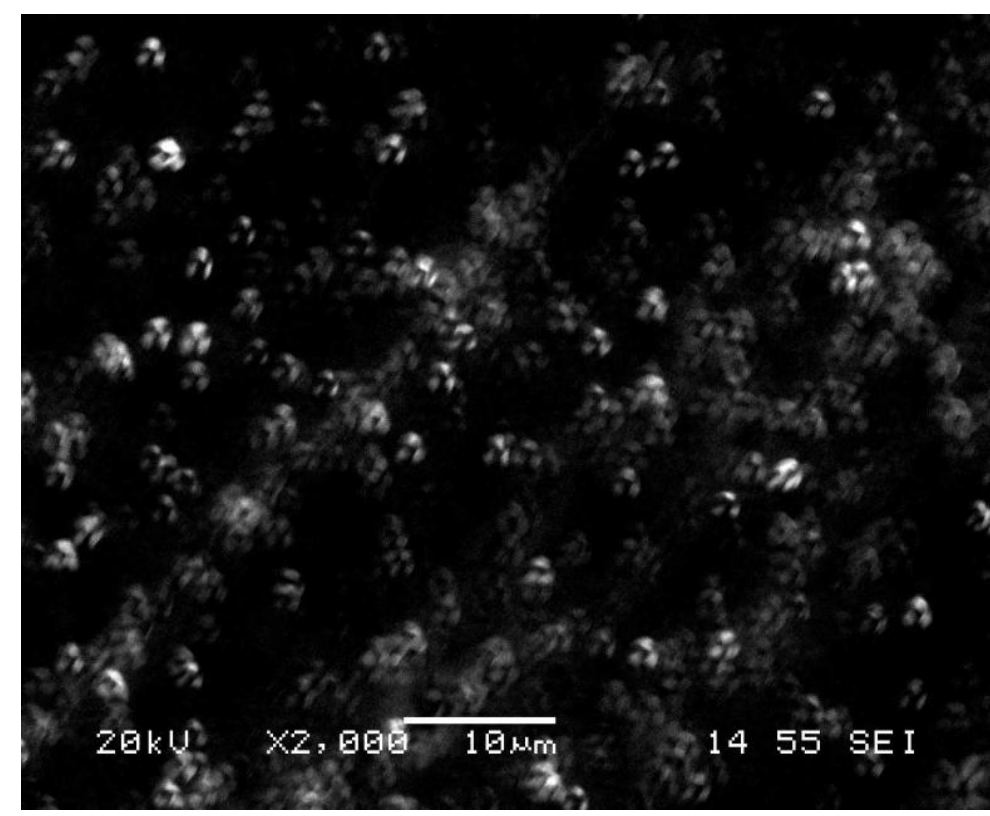

Figure 7 Sheared $\delta^{\prime}$ precipitates during planar dislocation movements.

The shearing of the $\delta^{\prime}$ precipitates and the local softening of the matrix results in strong plastic strain localization in the planar dislocations bands (Figure 7). Strongly sheared precipitates are seen within these bands (Figure 8 and Figure 8)

Dislocations were clearly revealed by transmission electron microscopy as well as the sheared $\delta^{\prime}$ precipitates resulting from the dislocations moving during the cyclic straining (Figure 8).

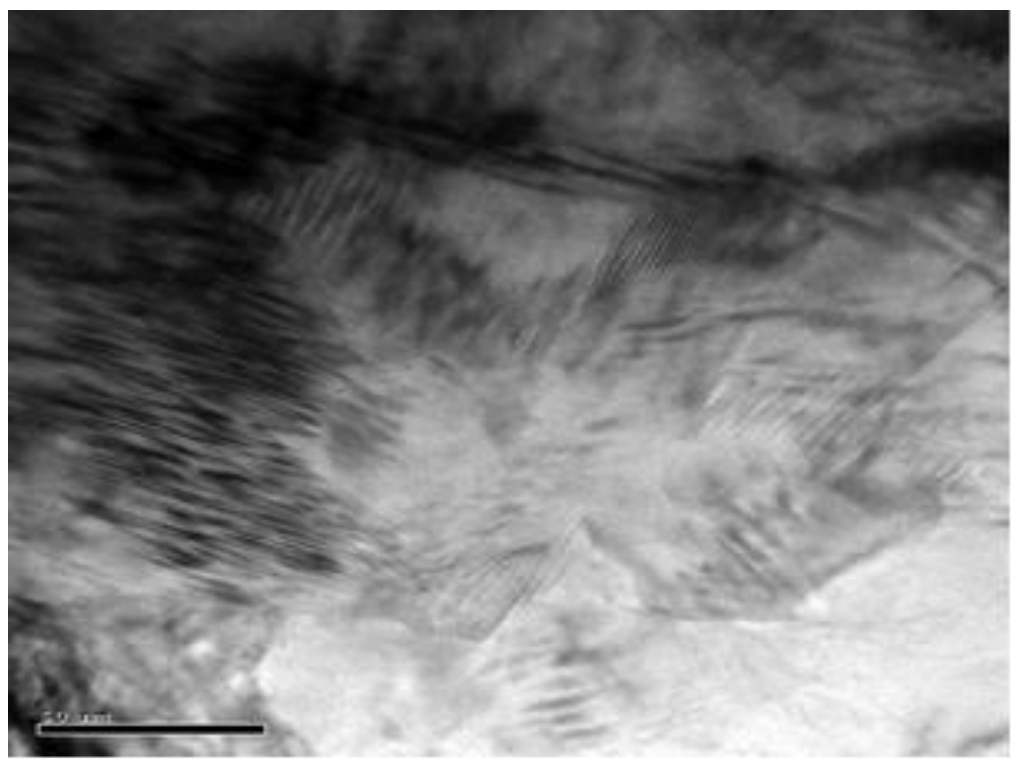

Figure 8 TEM micrograph showing numerous planar dislocation bands.

\section{CONCLUSION}

In this study, the tensile and low cycle fatigue tests behaviors of alloy $\mathrm{C} 460$ have been correlated with the type of dislocations and precipitates and their interactions. It was determined that strength and ductility in transverse and longitudinal directions reached maximum values during the process of cyclic straining, while ductility declined to minimum values, all three independently of the orientation of machining with respect to rolling direction. However, the yield strength in the longitudinal direction was higher than in the transverse direction. The $\delta^{\prime}$ precipitates are sheared as a result, of planar dislocation bands formed due to plastic strain localization. The cyclic hardening, saturation and cyclic softening were more pronounced at lower plastic strain amplitudes. 


\section{REFERENCES}

[1] Y.B. Xu, E.A. Starke, and R.P. Gangloff, Tensile deformation and fracture behavior of a rapidly solidified $\mathrm{Al}-\mathrm{Fe}-\mathrm{V}-\mathrm{Si}$ alloy at ambient and elevated temperature, Department of Materials Science and Engineering, University of Virginia, Unpublished report 1992.

[2] L. Zhen, D.Z. Yang, S.W. Sun, and G.F. Yu. Material Science Engineering A 248, 1998, 221-223.

[3] Y.B. Xua, W.L. Zhong, Y.J. Chen, L.T. Shen, Q. Liu, Y.L. Bai, and M.A. Meyers. Shear localization and recrystallization in dynamic deformation of 8090 Al-Li alloy, Materials Science and Engineering A, 299 2001, 287-295.

[4] R.S. Culver, R.W. Rhode, B.M. Butcher, J.R. Holland, and C.H. Karnes, Metallurgical effects at high strain rates, Plenum, New York, 1973, 518-519.

[5] R.J. Clifton, Material response to ultra-high-loading-rates, National Materials Advisory Board, N.A.S., Report NMAB356, 1979, 129-130.

[6] Y.B. Bai, M.A. Meyers, and L.E. Murr, Shock-wave and high-strain-rate phenomena, Plenum, New York, 1981, 277-278.

[7] S. Pappu, S. Niou, C. Kennedy, L.E. Murr, Duplessis, M.A. Meyers, L.E. Murr, K.P. Staudhammer (Eds.), Metallurgical and materials applications of shock-wave and high-strain-rate phenomena, Elsevier, Amsterdam, 1995, 487-496.

[8] H. Mughrabi, Cyclic stress-strain behavior, microstructure and fatigue life, proceeding of 6 th International Fatigue Congress, Berlin 1996, 57-68.

[9] T.H. Sanders, and E.A. Starke, Al-Li alloys V, Proceeding $5^{\text {th }}$ International Al-Li alloys Conference, T.H. Sanders, Jr., and E. A. Starke, Jr., eds., MCE Publications Ltd., Birmingham, United Kingdom, 1989, 1-37.

[10] M. Sundararaman, W. Chen, V. Singh and R.P. Wahi, TEM investigation of $\gamma$ ' free bands in nimonic PE16 under LCF loading at room temperature Acta Metallurgical 38, 1990, 2813-2825. 